Wright. Mr. Brundrett went to Sidney Sussex College, Cambridge, and obtained first-class honours (Wrangler) in the Mathematical Tripos. During 1916-19 he served in the R.N.V.R., and then was appointed to the scientific staff of H.M. Signal School, where he served in various capacities until 1937, his most outstanding original technical work being on the propagation of short wireless waves and in the organisation of world-wide propagation trials. In 1937 he was transferred to the Scientific Research and Experiment Department, Admiralty, as principal scientific officer, where a sequence of rapid promotions led to his becoming a deputy director of scientific research in 1942. In $1946 \mathrm{Mr}$. Brundrett was appointed assistant to the chief of the Royal Naval Scientific Service for the reconstruction period.

At the start of the Second World War, as many hundreds of scientific men throughout Great Britain will know from personal experience, Mr. Brundrett accomplished with great success a prodigious task in organising and recruiting a vast expansion of the Navy's scientific staff, and in the radar research branches of the other Services. He was throughout the War particularly prominent in the organisation and administration of radio valve research for the Services. He was honoured with the award of the C.B., in recognition of his war-time work, in the New Year Honours, 1946. Mr. Brundrett has a farm in Hampshire where he has achieved great success in the breeding of pedigree poultry and Red Poll cattle.

\section{Physics at King's College, London: Prof. C. A. Coulson}

DR. C. A. Coulson, recently appointed to the University chair of theoretical physics at King's College, London, is among the foremost workers in Great Britain on the wave-mechanical side of quantum theory. Although Coulson's research papers cover a very wide range of interests (he collaborated with Lea and Haines in early work on the action of radiation on bacteria and has also made contributions to the theory of liquids and solutions), the great bulk of his published work deals with the application of wave-mechanics to the theory of molecular structure. It has been concerned both with the determination of accurate wave-functions for simple molecules and molecular ions and with the necessarily more approximate treatment of large organic molecules. An extensive series of papers in collaboration with W. E. Duncanson deals with the rather neglected field of momentum distribution functions and the related Compton-line profiles.

In the theoretical treatment of large unsaturated molecules, Coulson uses the method of molecularorbitals originally due to Hückel and first developed in Britain by Prof. (now Sir John) Lennard-Jones at Cambridge. Coulson has used this method for a great variety of problems, from the computation of the bond-lengths of such a molecule as coronene to a calculation of the electrical conductivity of pure graphite. Recently, at Oxford, Coulson and his co-workers have made considerable advances towards an understanding of the effects of substituents in molecules and a general theory of chemical reactivity. In addition to his research papers, Dr. Coulson has also written text-books on the more elementary and elassical aspects of mathematical physics. He has a well-deserved reputation for his kindly and helpful encouragement of younger research workers.

\section{Food and Agriculture Organisation: Production and Research}

Dr. G. Scott Robertson, Permanent Secretary of the Ministry of Agriculture for Nprthern Ireland, has been seconded for a period of six months to take up the post of director of agricultural production and research under the Food and Agriculture Organisation of the United Nations. Dr. Scott Robertson went to Northern Ireland in 1922 and held the dual post of professor of agricultural chemistry in the Queen's University of Belfast and senior research officer of the Ministry of Agriculture. It was during this period that he continued the now classic work on phosphatic fertilizers which he had been conducting for several years in Essex while head of the Agricultural Chemistry Department of the East Anglian Institute of Agriculture. At the same time Dr. Scott Robertson started a series of investigations on the mineral requirements of farm livestock, paying particular attention to those of poultry. This work was carried, out in close collaboration with Sir John Boyd Orr, who was then director of the Rowett Research Institute. In 1928, Dr. Scott Robertson became chief inspector of the Ministry of Agriculture for Northern Ireland, and later was appointed permanent secretary when Dr. J. S. Gordon retired. For many years Dr. Robertson has acted as assessor on the Agricultural Research Council and United Kingdom delegate to the meetings of the Imperial Agricultural Bureaux. Thus he brings to his new work many years experience in agricultural research, coupled with administrative knowledge gained as head of a department the energies of which have been devoted to the task of production at the highest possible level for more than seven years.

\section{Research in the Region between Subsonic and Supersonic Speeds}

ThERE is a large gap in our knowledge which must be bridged before we can take decisive steps from present aircraft subsonic speeds to supersonic speeds. There is first of all the question as to what happens when actually passing through the range of speed about that of sound. It is known that we must expect a steep rise of drag in this region, but we have no quantitative information. There is the further question of change of trim and stability in level flight as one passes from subsonic to supersonic speeds. There are other questions of aerodynamic and structural significance, and the whole problem is rather complex. Normally one would expect to get a large part of this information from wind tunnels, and although the capabilities of existing wind tunnels will be used to the limit, nobody knows how to design or use a practicable wind tunnel at or about the speed of sound. The phenomenon known as 'choking' and the effect of wall interference pro. hibit the use of tunnels for model tests at Mach numbers between about 0.9 and $1 \cdot 15$. This is the main reason for going into the air, and a series of experiments has been planned to use flying model aircraft launched from a great height from another aircraft and powered by rockets. This form of propulsion should enable the models to be driven through the speed-range of that of sound to various supersonic speeds.

The models will be fitted with instruments, and a six-channel telemetering system will transmit readings continuously to the ground, giving information on speed, height, Mach number, drag, lift coefficient and 
longitudinal trim. Radar observations will also be made on the flight path. All this involves a new research technique, and early experiments will be mainly concerned with perfecting it. Step by step it is hoped to reach the position where enough information will be available to design a supersonic radio-controlled aircraft. The rocket thrust is about $850 \mathrm{lb}$. acting for some 70 sec. An auto-pilot controls the model in pitch and roll. It is proposed to release the model at $36,000 \mathrm{ft}$. from a Mosquito aircraft, when the controls will operate to cause it to glide down to $35,000 \mathrm{ft}$. The rocket motor will then be switched on to accelerate the model in roughly level flight, at this height, to an estimated Mach number of about $1 \cdot 3$. When the fuel is all burnt the model will decelerate, its speed passing through that of sound to subsonic velocity; so a double chance will occur of getting readings in the critical transonic region before the automatic controls operate to crash the model into the sea. The models have been designed by Mr. B. N. Wallis, of Vickers-Armstrong, and made there in collaboration with the Royal Aircraft Establishment, which is responsible for the conduct of these experiments. The experiments should start in about a month's time off the Scilly Isles.

\section{Chemistry at the University of Sheffield}

The Staveley Coal and Iron Co., Ltd., near Chesterfield, has decided to make a gift of $£ 50,000$ to the University of Sheffield in order to promote the furtherance of research within the University and especially in the Department of Chemistry. The Company, which is concerned with the production of iron, caustic soda, chlorine, hydrochloric acid, chlorates, aniline and a wide range of basic coal-tar products, takes the view that encouragement of free chemical research in universities must, in the long run, benefit both the Company and industry as a whole, and believes that the connecting of industrial development with academic discovery is essential for national prosperity. Its gift to Sheffield is most opportune, as the provision of a new Department of Chemistry is one of the most urgent parts of the post-war plans of the University's extension scheme. It is intended to replace the existing laboratories, built in 1905 , by an entirely new department which will be close to the present building of the University in Western Bank. The new building has been designed to provide adequate space for all the work in the Department when the University attains its projected number of 3,000 full-time students in all faculties, and adequate research facilities will be provided for investigations in analytical, inorganic, physical and organic chemistry. It is estimated that the cost of the erection of the new Department will exceed $£ 400,000$, and it is proposed that the research laboratories therein should be named the "Staveley Laboratories".

\section{A New Rat Poison}

To the well-known list of rat poisons, such as arsenic trioxide, red squill and zinc phosphide, the last years of the War added another, $\alpha$-naphthathiourea. Dr. C. P. Richter, of Baltimore, was responsible for showing that its toxicity to Rattus norvegicus was high (A.L.D./50, $10 \mathrm{mgm}$. per kilo body-weight). Somewhat extravagant claims were made for its effectiveness when applied as a direct bait. In none of the field tests were accurate censuses made of the rat population before treatment. Prolonged and detailed experience in Great Britain at the Bureau of Animal Population has shown that knowledge obtained by bait census is essential before field trials are undertaken. The use of $\alpha$-naphtha. thiourea as a dusting powder, however, opened up possibilities of a new method of application, but its usefulness depended upon the safety factor involved. Toxicity tests made on other animals showed an enormous range of sensitivity. $R$. rattus, the ship or black rat, had an A.L.D. $/ 50$ of $250+$ mgm. per kilo body-weight, more than twenty-five times that for $R$. norvegicus, while Mus musculus, the house mouse, had an A.L.D./50 of 80-90 mgm. per kilo body-weight. These data showed that it was impossible to predict a safety-level from one species to another. Consequently, although tests on monkeys (Macacus sp.) showed a high resistance, it was dangerous to assume that man was equally immune. Dusting application was therefore not advised in Great Britain until more information was available.

Used in baits, following the pre-baiting technique worked out by the Bureau of Animal Population, $\alpha$-naphthathiourea gave results as good as those with arsenic and zinc phosphide, namely, 90 per cent kills ; used as a direct bait without prebaiting, some successes were met with, but also the usual failures (for example, 40 per cent kill). Since the failure to exterminate rats is largely due to the hit and miss nature of direct baiting which has been employed for so long, there seemed no grounds for regarding $\alpha$-naphthathiourea as any considerable advance on the well-established poisons. $\alpha$-Naphthathiourea is now being marketed by the Rodmill Chemical Co., Ltd., as 'Antu', containing 2 per cent of the active principle. As a ready-to-use compound bait, 'Antu' must be classed with the direct baits which do not allow the purchasing public to pre-bait and ensure success. It is also being recommended as a dusting powder for use in rat runs, on beams and elsewhere "inaccessible to domestic animals"-places which may be hard to find. From the point of view of rodent control, it is to be regretted that $\alpha$-naphthathiourea is not being marketed at a 20 per cent concentration in an inert medium and so allowing the public to obey the recommendations of the Infestation Division of the Ministry of Food to pre-bait before poisoning, a technique worked out by the Bureau of Animal Population during the War, which has proved itself again and again to be the only really certain way of exterminating rats.

\section{Exhibition of Applied Photography}

AN Exhibition of Applied Photography arranged by Kodak Ltd. at Australia House, Strand, London, was opened on May 6 by Prof. E. N. da C. Andrade. The exhibits illustrate a very wide range of industrial and commercial applications of photography, the applications being illustrated by photographs, diagrams and in some cases demonstrations. Photography received a fair amount of publicity during the War, particularly on account of its obvious importance for air reconnaissance. There were, however, many other applications less spectacular, but nevertheless of great value, many of which are illustrated in some form in this exhibition. Most of these applications have come to stay and will play a useful part in peace-time industry. The range covered by the exhibition is very wide; on the spectacular side is a full-sized radiograph of a 'Jeep' to set against the purely utilitarian micro-copying of documents. Other exhibits include industrial radiography, gamma radiography, stereoscopy, photography in education, colour reproduction and the reproduction of drawings 